\title{
Characteristics and treatment outcomes of patients with primary ocular adnexal lymphoma in Northern Thailand
}

\author{
Kasem Seresirikachorn ${ }^{1}$, Sakarin Ausayakhun', \\ Damrong Wiwatwongwana ${ }^{1}$, Ponsak Mahanupab², Teerada \\ Daroontum ${ }^{2}$, Lalita Norasetthada ${ }^{3}$ \\ 'Department of Ophthalmology, Faculty of Medicine, Chiang Mai University, \\ Chiang Mai, Thailand; '2Department of Pathology, Faculty of Medicine, Chiang \\ Mai University, Chiang Mai, Thailand; ' ${ }^{2}$ ivision of Hematology, Department \\ of Medicine, Faculty of Medicine, Chiang Mai University, Chiang Mai, Thailand
}

\begin{abstract}
Purpose: To assess the characteristics and treatment outcomes of patients with primary ocular adnexal lymphoma (OAL) in Northern Thailand.

Design: Retrospective cohort study.

Methods: Data was collected from electronic medical records and operative notes from Chiang Mai University Hospital between January 2009 and December 2014. All available tissue biopsies of 54 patients were reviewed by agreement of two pathologists. The clinical characteristics and treatment outcomes were collected and analyzed.

Results: A total number of 54 patients were identified of which $57.4 \%$ were female. The median age was 61.0 years (range, 4-86). The most common subtype of lymphoma was extranodal marginal zone lymphoma (ENMZL) of mucosa-associated lymphoid tissue (MALT) ( $n=46$, 85.2\%). Seventy-five percent of the patients presented with a mass at the ocular adnexa, while $14.8 \%$ of the patients presented with proptosis. The sites of origin were as follows: lacrimal (46.3\%), orbit (31.5\%), conjunctiva (13\%) and eyelid (7.4\%). Two-thirds of the patients had Ann-Arbor Stage I, while 22\% of patients had Stage IV. The majority of the patients (68.1\%) had a low-risk international prognosis index (IPI). Treatment modalities involved field radiation (IFRT, 50\%), chemotherapy (31.6\%), combined chemoradiotherapy (7.9\%) and surgical resection (10.5\%). The overall response rate was $100 \%$ with a complete response rate of $77.8 \%$. In patients with low-grade lymphoma, including MALT lymphoma, the 3-year progressionfree survival (PFS) and overall survival were $69.9 \%$ and $92.5 \%$, respectively.

Conclusion: ENMZL of MALT was the major subtype of primary OAL. Radiotherapy was an effective treatment for the lower stages of disease providing a high response rate and encouraging survival outcomes.
\end{abstract}

Keywords: extranodal marginal zone lymphoma of mucosal-associated lymphoid tissue, ocular adnexal lymphoma, radiotherapy, treatment modalities

Correspondence: Kasem Seresirikachorn, MD, Department of Ophthalmology, Tambon Sripoom, Amphur Muang, 110 Inthawarorot Road, Chiang Mai, Thailand 50200.

E-mail: chimm chimm@hotmail.com 


\section{Introduction}

Primary ocular adnexal lymphoma (OAL) is the most common malignancy of the eye. ${ }^{1}$ Primary OAL is defined as lymphoma that occurs at the conjunctiva, lacrimal apparatus, eyelid and in the orbit. OAL comprised $2 \%$ of non-Hodgkin lymphoma and $8 \%$ of extranodal lymphoma. ${ }^{2}$ The most common subtype is extranodal marginal zone lymphoma (ENMZL) of mucosa-associated lymphoid tissue (MALT), which usually originates from B cells., ${ }^{3,4}$ The most frequent site of origin is the orbit $40 \%$, conjunctiva $35 \%$ to $40 \%$, lacrimal apparatus $10 \%$ to $15 \%$ and eyelid $10 \%$. The average age for diagnosis is from 50 to 70 years. Bilateral disease will be seen in $10 \%$ to $15 \% .^{5}$

Most of the patients (85-90\%) were diagnosed with Ann-Arbor Stage I which responded very well to radiotherapy. ${ }^{6} \mathrm{~A}$ complete response rate was $85 \%$ to $90 \%$, and only $10 \%$ to $15 \%$ of the patients had Ann-Arbor Stage IV. ${ }^{7,8}$ Currently, there are no standard treatment guidelines specifically for OAL. Patients were treated as ENMZL lymphoma in the other sites. Patients with Stage I disease were commonly treated with involved field radiotherapy.

The majority of previous reports were from Western countries. In Thailand, there were few publications regarding primary OAL..${ }^{9} 10 \mathrm{To}$ improve the diagnosis and quality of treatment in a patient with OAL, we conducted a retrospective review to study the characteristics and treatment outcomes of OAL patients in Northern Thailand.

\section{Material and methods}

This study was approved by the Institutional Review Board of Chiang Mai University Hospital, Chiang Mai, Thailand. The medical records and operative notes between January 2009 and December 2014 were reviewed to recruit patients with OAL. The inclusion criteria of patients in this study were patients diagnosed with OAL between January 2009 and December 2014 who had been followed for at least 1 year. The patients with follow-up of less than 1 year were excluded from the study. All available tissue biopsies of these patients were reviewed by two pathologists according to the 2008 World Health Organization guidelines. Immunohistochemical study routine was done to identify the subtype of lymphoma which included CD3, CD5, CD10 and CD20; however, because of the limitation of resource and available tissues, we cannot perform genetic study, but both of the experienced pathologists had a consensus agreement with the diagnosis with available tissues.

Data were collected including age at diagnosis, gender, underlying disease, clinical presentation, time to diagnosis, procedure of tissue biopsy, anatomical location, laterality, subtype of OAL, immunophenotype, Ann-Arbor staging, number of extranodal sites and performance status (ECOG). Additional data included serum 
lactic dehydrogenase (LDH) level, anti-HIV, hepatitis B and C status, international prognostic index (IPI) and treatment modalities including type of chemotherapy, radiotherapy, response to treatment, recurrent status of disease, salvage therapy and current status of the patients. All treatment outcomes were evaluated for at least 1 year and disease activity was evaluated at the last time of follow-up.

\section{Statistical analysis}

The demographic and response rates were analyzed with descriptive statistics. Overall survival (OS) was measured from the date of diagnosis to the date of last follow-up or death from any cause. Progression-free survival (PFS) was calculated from the date of diagnosis to the date of last follow-up, second relapse/progression or death from any cause. Probabilities of OS and second PFS were estimated by using the Kaplan-Meier method and using log-rank test for survival comparison. All statistical analyses were performed using SPSS 16.0 for Windows (SPSS, Chicago, IL).

\section{Results}

\section{Patients}

Fifty-four patients were identified with primary OAL between January 2009 and December 2014. Demographic and clinical characteristics of primary OAL are summarized in Table 1. There were 31 females (57.4\%) with a median age of 61 years (range, 4-86 years). The most common subtype of lymphoma was ENMZL of MALT ( $n=46,85.2 \%)$. Other histologic subtypes included diffuse large B-cell lymphoma (DLBCL, $n=3,5.6 \%$ ), peripheralT-cell lymphoma (PTCL, $n=3,5.6 \%)$, MALT lymphoma with large cell transformation $(n=1)$ and small lymphocytic lymphoma $(S L L, n=1)$.

A palpable mass was the main presenting symptom (75.9\%). Other manifestations were proptosis (14.8\%), cellulitis (5.6\%) and eye pain (3.7\%). The median interval between onset of the first symptoms and the date of diagnosis was five months (range, 0.5-84 months). Anatomically the tumors were distributed as follows: lacrimal (46.3\%), orbit (31.5\%), conjunctiva (13\%) and eyelid (7.4\%). Most of the patients present with unilateral (75.9\%). The primary immunophenotype was B-cell origin (94.4\%).

At presentation, 32 (59.3\%) patients had Ann-Arbor Stage I, six (12\%) patients had Ann-Arbor Stage II, one patient had Ann-Arbor Stage III and 11 (22\%) patients had Ann-Arbor Stage IV. Fifty-two patients (96.3\%) had ECOG 0; therefore, the majority of patients with OAL were fully active and able to carry on all pre-disease activities without restriction.

Only two (4.8\%) patients were previously diagnosed with HIV before presenting with primary OAL. The majority of the patients had a normal serum LDH level (94\%) and lower-risk IPI (80.9\%). There were few patients with HBV $(n=1)$ and $\mathrm{HCV}(n=1)$ infection. 
Seresirikachorn, et al.

Table 1. Demographic and clinical characteristics of primary OAL

\begin{tabular}{|c|c|}
\hline Characteristics & Number of patients (\%) \\
\hline Median age of diagnosis & 61.0 years (range, $4-86$ ) \\
\hline Female & $31(57.4 \%)$ \\
\hline $\begin{array}{l}\text { Clinical presentation } \\
\text { - Palpable mass } \\
\text { - Proptosis } \\
\text { - Cellulitis } \\
\text { - Eye pain }\end{array}$ & $\begin{array}{l}41(75.9 \%) \\
8(14.8 \%) \\
3(5.6 \%) \\
2(3.7 \%)\end{array}$ \\
\hline Median time to diagnosis & 5.0 months (range, $0.5-84$ ) \\
\hline $\begin{array}{l}\text { Anatomical location } \\
\text { Lacrimal } \\
\text { Orbit } \\
\text { Conjunctiva } \\
\text { Eyelid } \\
\text { Lacrimal and conjunctiva }\end{array}$ & $\begin{array}{l}25(46.3 \%) \\
17(31.5 \%) \\
7(13 \%) \\
4(7.4 \%) \\
1(1.9 \%)\end{array}$ \\
\hline Laterality: Unilateral & $41(75.9 \%)$ \\
\hline $\begin{array}{l}\text { Subtype of lymphoma } \\
\text { - MALT lymphoma } \\
\text { - DLBCL } \\
\text { - PTCL } \\
\text { - MALT lymphoma with large cell transformation } \\
\text { - SLL }\end{array}$ & $\begin{array}{l}46(85.2 \%) \\
3(5.6 \%) \\
3(5.6 \%) \\
1(1.9 \%) \\
1(1.9 \%)\end{array}$ \\
\hline Immunophenotype: B-cell origin & $51(94.4 \%)$ \\
\hline $\begin{array}{l}\text { Ann-Arbor staging } \\
\text { - I } \\
\text { - II } \\
\text { - III } \\
\text { - IV }\end{array}$ & $\begin{array}{l}32(64 \%) \\
6(12 \%) \\
1(2 \%) \\
11(22 \%)\end{array}$ \\
\hline $\begin{array}{l}\text { Performance status (ECOG) } \\
\quad \cdot 0 \\
\cdot 1\end{array}$ & $\begin{array}{l}52(96.3 \%) \\
2(3.7 \%)\end{array}$ \\
\hline $\begin{array}{l}\text { IPI } \\
\text { - Low risk } \\
\text { - Low-intermediate risk } \\
\text { - High-intermediate risk } \\
\text { - High risk }\end{array}$ & $\begin{array}{l}32(68.1 \%) \\
6(12.8 \%) \\
7(14.9 \%) \\
2(4.3 \%)\end{array}$ \\
\hline
\end{tabular}


Primary ocular adnexal lymphoma in Northern Thailand

\begin{tabular}{|l|l|}
\hline Characteristics & Number of patients (\%) \\
\hline LDH level: normal (<246)/high & $45(93.8 \%) / 3(6.2 \%)$ \\
\hline HIV status: positive & $2(4.8 \%)$ \\
\hline HBV infection: positive & $1(2.4 \%)$ \\
\hline HCV infection: positive & $1(2.4 \%)$ \\
\hline
\end{tabular}

\section{Treatment and outcomes}

Treatmentmodalities wereasfollows:IFRT (50\%), chemotherapy(31.6\%), combined chemoradiotherapy (7.9\%) and surgical resection (10.5\%). The most common regimen for chemotherapy was $\mathrm{CHOP}$ which was comprised of cyclophosphamide, doxorubicin, vincristine and prednisolone (40\%). The other regimens were CP (chlorambucil and prednisolone, 26.7\%), CVP (cyclophosphamide, vincristine and prednisolone, $20 \%$ ), and ALL protocol $(n=1)$ (Table 2$)$.

Treatment outcomes were categorized according to the subtype and staging of lymphoma (Table 3). Indolent lymphoma included ENMZL of MALT and SLL, while aggressive lymphoma comprised of DLBCL, PTCL and MALT lymphoma with large cell transformation. The response rate after treatment in patients either with indolent and aggressive lymphoma was $100 \%$. Eleven $(20.4 \%)$ patients in this study had disease progression or relapse. The 3-year PFS and OS of patients with indolent lymphoma were 69.9 and $92.5 \%$, respectively, which appeared to be better than of those with aggressive lymphoma (3-year PFS and OS of 42.9\% [p = 0.12] and 42.9\% [p < 0.0001]) (Fig. $1 \mathrm{~A}$ and $\mathrm{B}$ ).

Table 2. Treatment modalities

\begin{tabular}{|l|l|l|}
\hline Treatment modalities & Watch and wait $(\mathbf{n}=\mathbf{1 6})$ & Treatment $(\mathbf{n}=\mathbf{3 8})$ \\
\hline Radiotherapy & & $19(50 \%)$ \\
\hline Chemotherapy & & $12(31.6 \%)$ \\
CHOP & & 5 \\
CVP & & 3 \\
CP & 3 \\
ALL protocol & & 1 \\
\hline Surgery & & $4(7.9 \%)$ \\
\hline Chemotherapy and radiotherapy & & $3(10.5 \%)$ \\
\hline
\end{tabular}


Table 3. Treatment outcomes categorized according to subtype and staging of lymphoma

\begin{tabular}{|c|c|c|c|c|c|c|c|}
\hline Type of lymphoma & Staging & $\mathbf{N}$ & OR (\%) (CR, \%) & \multicolumn{2}{|c|}{ 3-year PFS (\%) } & \multicolumn{2}{|c|}{ 3-year OS (\%) } \\
\hline \multirow[t]{2}{*}{ Indolent lymphoma } & $|-| \mid$ & 26 & $100(76.9)$ & 70.2 & \multirow[t]{2}{*}{69.9} & 96.8 & \multirow[t]{2}{*}{92.5} \\
\hline & III-IV & 5 & $100(60)$ & 55.6 & & 50.0 & \\
\hline \multirow[t]{2}{*}{ Aggressive lymphoma } & $\mid-I I$ & 3 & $100(100)$ & 33.3 & \multirow[t]{2}{*}{42.9} & 33.3 & \multirow[t]{2}{*}{42.9} \\
\hline & III-IV & 2 & 100 (100) & 66.7 & & 66.7 & \\
\hline
\end{tabular}

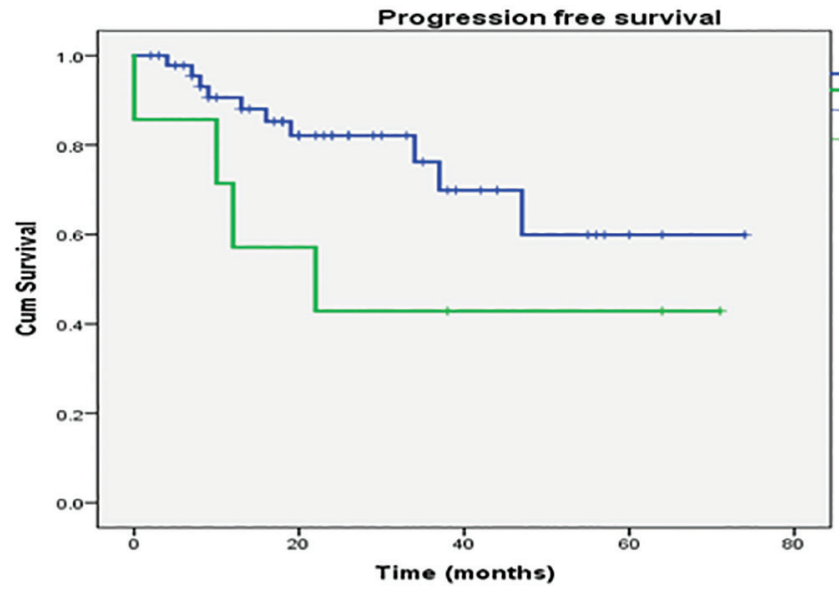

indolent/aggresive

Tindolent tymphoma

Aggresive lymphoma

- Indolont tymphoma-

Aggrosive lymphoma

(months)

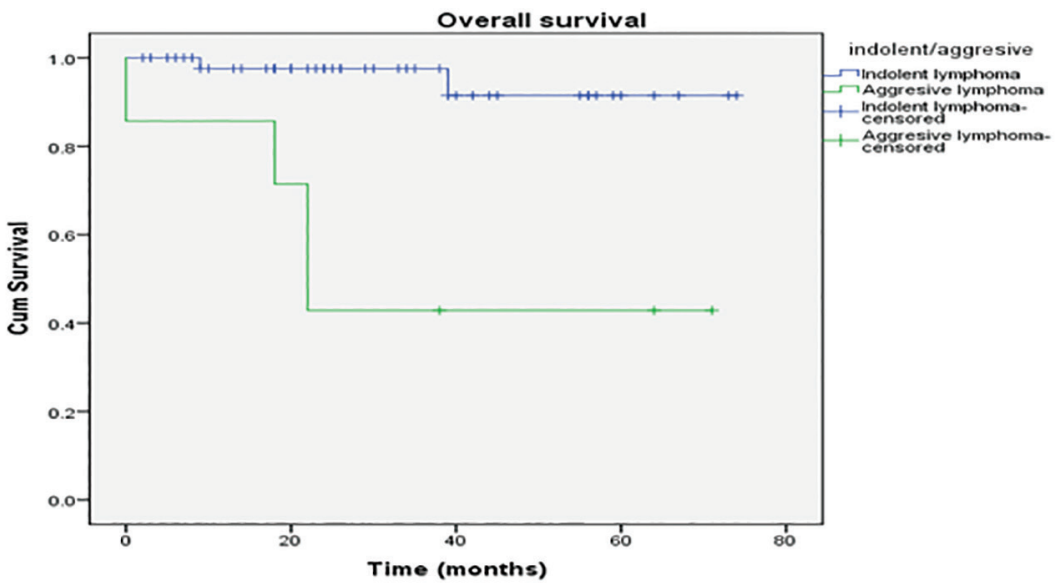

Fig. 1. (A) Kaplan-Meier PFS according to clinical subtypes of symptoms. (B) Kaplan-Meier OS according to clinical subtypes of lymphoma. 
For patient with limited stage indolent lymphoma, either unilateral or bilateral ocular adnexal involvement had no significant effect on event-free survival (EFS) and OS, although patient with unilateral involvement had a trend of better EFS (median EFS was not reached) than those with bilateral involvement (EFS $=29$ months, $p=0.025$ ). Moreover, in this particular group patients, anatomical involvement had no effect on both EFS and OS ( $p=0.66$ )

Among patients with indolent lymphoma, those with lower stages of disease had a superior 3-year PFS (70.2\%) and 3-year OS (96.8\%) than those with advanced stage disease with 3-year PFS and OS of $55.6 \%$ and $50 \%$, respectively.

\section{Discussion}

Over the past decade, patients suspected to have primary OAL were transferred to Chiang Mai University Hospital, which is a tertiary care hospital in Northern Thailand. A multidisciplinary team was composed of an ophthalmologist, haematologist, pathologist and radiotherapists. With limited information on the patient treatment modalities and outcomes, it was difficult to explain to the patients regarding their disease status and prognosis. This study will provide a better understanding of patient characteristics and long-term outcomes after therapy.

The most common subtype of OAL in this study was ENMZL of MALT. Interestingly in our study, there was a higher proportion of patient of MALT lymphoma (85.2\%) when compared with previous reports from the Asian and Western countries in which MALT lymphoma shows $30 \%$ to $70 \%$ of OAL ${ }^{11-16}$ (Table 4). A palpable mass was the most common manifestation with a wide range of times from the first sign of symptoms to diagnosis of 0.5 to 84 months. This may be explained by the non-painful and slow progress of the disease. OAL commonly occurred in elderly patients which correlated with previous studies. ${ }^{11-15,17-19}$

Meunier et al.,12 found that elevated LDH in low-grade lymphoma patients negatively predicted disease-free survival; however, in this series, most of the patients (93.8\%) had a normal volume of LDH. Ferreri et al..$^{20,21}$ demonstrated an association between Chlamydia psittaci and OAL, but in our study, we have a limited number of tissues and methods to detect $C$. psittaci; therefore we did not find this association.

The most common site of origin was the lacrimal gland, which was different from previous studies, ${ }^{12,14,16,17-19}$ but correlated with a previous study in Thailand. ${ }^{10}$ Most of the patients had Ann-Arbor Stage I and radiotherapy was the first-line treatment option which concurred with previous reports. ${ }^{12,14,15,17-19}$ Rituximab, anti-CD20 antibody, has been reported to have a good activity on OAL. ${ }^{22-28}$ Due to its high cost, there was only one patient in this cohort who received rituximab with complete response after treatment. 
In this study, an indolent subtype of primary OAL had an excellent outcome with a 3-year PFS and OS of $69.9 \%$ and $92.5 \%$, respectively. Of these patients with indolent lymphoma, those with a limited stage had superior survival than those with advanced stage disease. Lymphoma is a chemo- and radio-sensitive disease; therefore, both aggressive and indolent lymphoma showed a good response rate after treatment. However, aggressive lymphoma nature had a high chance of progression and relapse disease afterward. Many studies from Western and Asian countries also showed similar outcomes with high PFS and OS after radiotherapy. ${ }^{11,12,14,15,18,19}$

This study had several limitations. First, it was retrospective in nature; therefore, there was a limitation in data collection. Second, ocular adnexa was not a common site of aggressive lymphoma, so we were not able to find a predicting prognosis factor in this subgroup of lymphoma. In the future, we should find a prognosis factor and association with C. psittaci in a larger study and focus on ENMZL of MALT which are the most common subtypes. The appropriate dosage of radiation and complications should also be further explored.

In conclusion, in Northern Thailand, ENMZL of MALT was the most common subtype of primary OAL. In a limited stage of disease, initial treatment with radiotherapy provided excellent outcomes. 


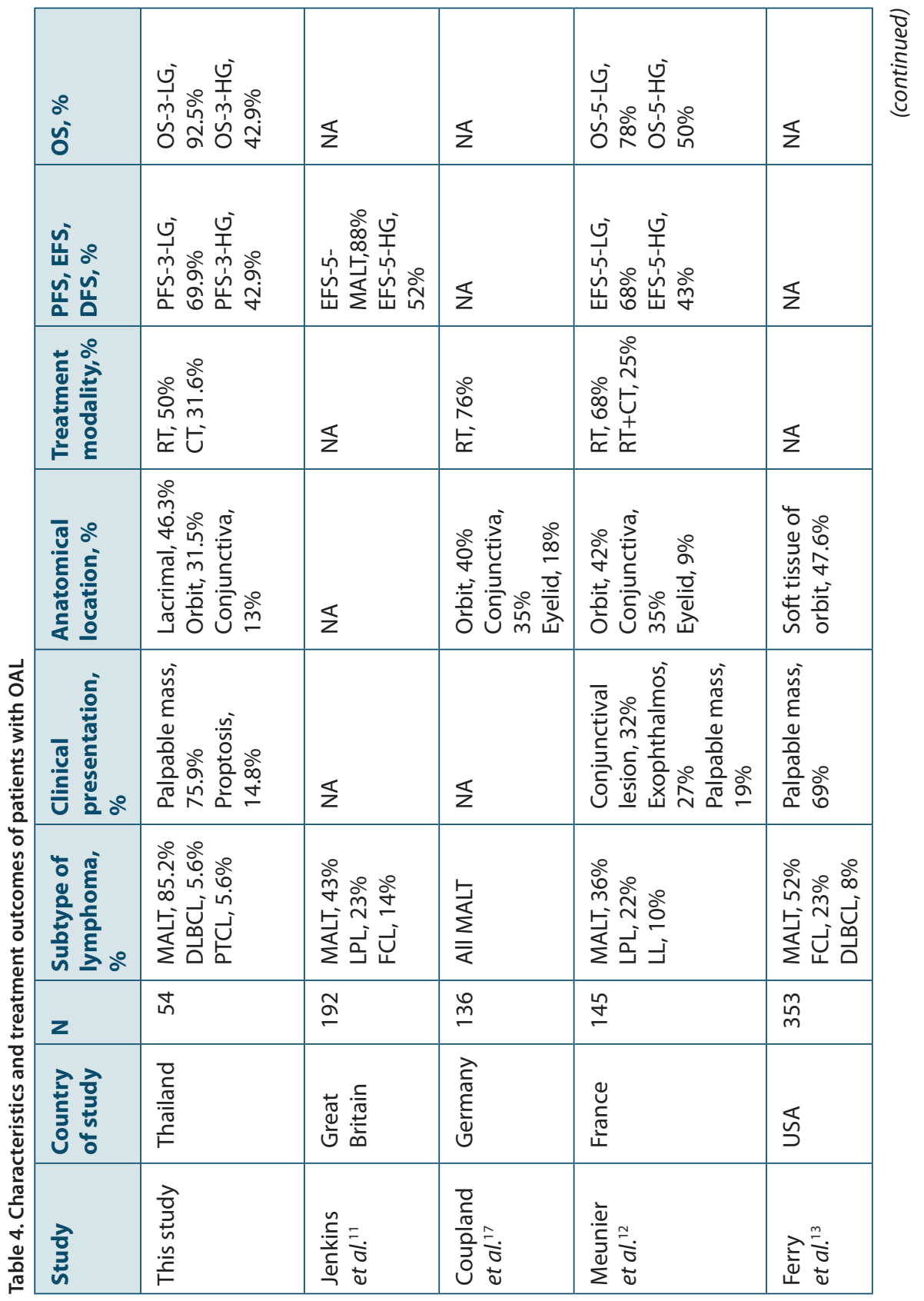


Seresirikachorn, et al.

\begin{tabular}{|c|c|c|c|c|}
\hline $\begin{array}{l}\text { กั } \\
\text { ปे }\end{array}$ & 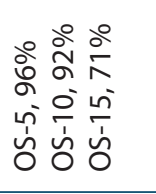 & $\Sigma$ & 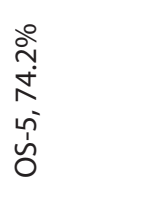 & 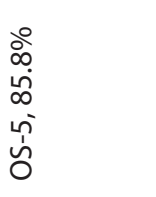 \\
\hline 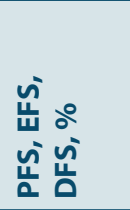 & 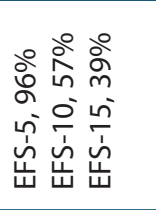 & 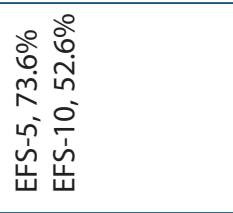 & $\Sigma$ & 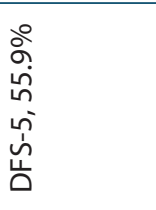 \\
\hline 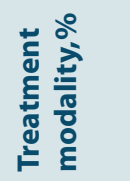 & $\begin{array}{l}\frac{\circ}{i n} \\
\frac{1}{x}\end{array}$ & 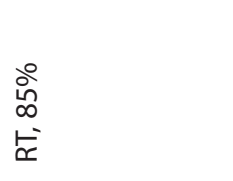 & 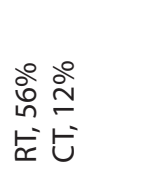 & 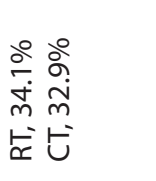 \\
\hline 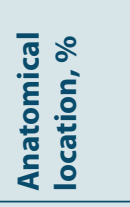 & 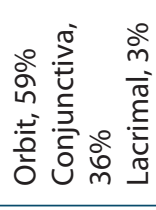 & 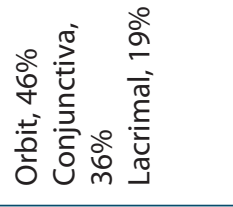 & 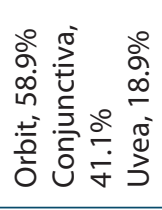 & $\Sigma$ \\
\hline 厄. & $\Sigma$ & 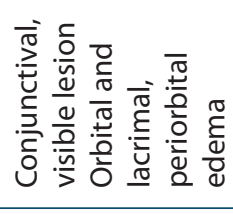 & $\Sigma$ & $\Sigma$ \\
\hline 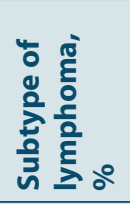 & 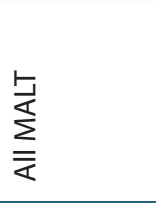 & 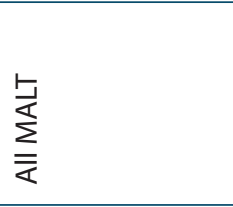 & 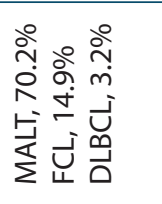 & 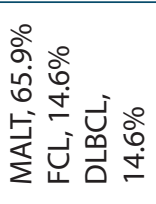 \\
\hline$z$ & $\stackrel{ \pm}{\rightleftarrows}$ & ৪ & n̊ & న \\
\hline 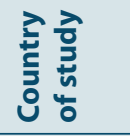 & $\begin{array}{l}\frac{c}{\pi} \\
\stackrel{\frac{0}{\pi}}{\frac{\pi}{n}}\end{array}$ & 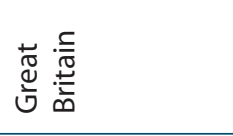 & હે & ๓ు \\
\hline 훌 & 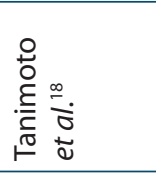 & 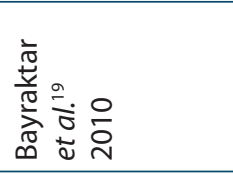 & 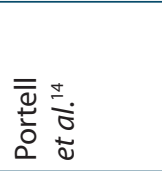 & 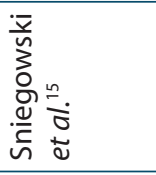 \\
\hline
\end{tabular}

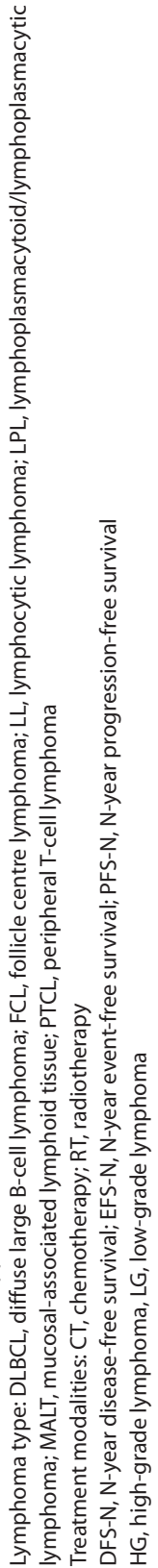




\section{References}

1. Margo CE, Mulla ZD. Malignant tumors of the orbit: analysis of the Florida Cancer Registry. Ophthalmology. 1998;105:185-190.

2. Freeman C, Berg JW, Cutler SJ. Occurrence and prognosis of extranodal lymphoma. Cancer. 1972;29:252-260.

3. White WL, Ferry JA, Harris NL, Grove AS, Jr. Ocular adnexal lymphoma: a clinicopathologic study with identification of lymphomas of mucosa-associated lymphoid type. Ophthalmology. 1995;102:1994-2006.

4. McKelvie PA, McNab A, Francis IC, Fox R, O'Day J. Ocular adnexal lymphoproliferative disease: a series of 73 cases. Clin Exp Ophthalmol. 2001;29:387-393.

5. Ferreri AJ, Dolcetti R, Du MQ, et al. Ocular adnexal MALT lymphoma: an intriguing model for antigen-driven lymphomagenesis and microbial-targeted therapy. Ann Oncol. 2008;19:835-846.

6. Rosado MF, Byrne GE Jr, Ding F, et al. Ocular adnexal lymphoma: a clinicopathologic study of a large cohort of patients with no evidence for an association with Chlamydia psittaci. Blood. 2006;107:467-472.

7. Le QT, Eulau SM, George TI, et al. Primary radiotherapy for localized orbital MALT lymphoma. Int J Radiat Oncol Biol Phys. 2002;52:657-663.

8. Tsang, RW, Gospodarowicz MK, Pintilie M, et al. Localized mucosa-associated lymphoid tissue lymphoma treated with radiation therapy has excellent clinical outcome. J Clin Oncol. 2003;21:4157-4164.

9. Tulvatana W, Paisuntornsug T, Keelawat S, Sansopha L, Karnsawai S. Malignant tumors of the eye and ocular adnexa at King Chulalongkorn Memorial Hospital: a twelve-year review (1988-1999). Chulalongkorn Med J. 2001;45(4):283-293.

10. Na Pombejara F, Tulvatana W, Pungpapong K. Malignant tumours of the eye and ocular adnexa in Thailand: a six-year review at King Chulalongkorn Memorial Hospital. Asian Biomed. 2009;3(5):551-555.

11. Jenkins $C$, Rose $G E$, Bunce $C$, et al. Histological features of ocular adnexal lymphoma (REAL classification) and their association with patient morbidity and survival. $\mathrm{Br} J$ Ophthalmol. 2000;84:907-913.

12. Meunier J, Lumbroso-Le RL, Vincent-Salomon A, et al. Ophthalmologic and intraocular non-Hodgkin's lymphoma: a large single center study of initial characteristics, natural history, and prognostic factors. Hematol Oncol. 2004;22:143-158.

13. Ferry JA, Fung CY, Zukerberg L, et al. Lymphoma of the ocular adnexa: a study of 353 cases. Am J Surg Pathol. 2007;31:170-184.

14. Portell CA, Aronow ME, Rybicki LA, Macklis R, Singh AD, Sweetenham JW. Clinical characteristics of 95 patients with ocular adnexal and uveal lymphoma: treatment Outcomes in Extranodal Marginal Zone Subtype. Clin Lymphoma Myeloma Leuk. 2014;14(3):203-210.

15. Sniegowski MC, Robert D, Bakhoum M, et al. Ocular adnexal lymphoma: validation of American Joint Committee on Cancer seventh edition staging guidelines. Br J Ophthalmol. 2014;98:1255-1260.

16. Asadi-Amoli F, Nozarian Z, Bonaki HN, Mehrtash V, Entezari S. Clinicopathologic assessment of ocular adnexal lymphoproliferative lesions at tertiary eye hospital in Iran. Asian Pac J Cancer Prev. 2016;17(8):3727-3731.

17. Coupland SE, Hellmich M, Auw-Haedrich C, Lee WR, Anagnostopoulos I, Stein H. Plasmacellular differentiation in extranodal marginal zone B cell lymphomas of the ocular adnexa: an analysis of the neoplastic plasma cell phenotype and its prognostic significance in 136 cases. $\mathrm{Br}$ J Ophthalmol. 2005;89:352-359.

18. Tanimoto K, Kaneko A, Suzuki S, et al. Primary ocular adnexal MALT lymphoma: a long-term follow-up study of 114 patients. Jpn J Clin Oncol. 2007;37:337-344. 
19. Bayraktar S, Bayraktar UD, Stefanovic A, Lossos IS. Primary ocular adnexal mucosa-associated lymphoid tissue lymphoma (MALT): single institution experience in a large cohort of patients. Br J Haematol. 2010;152:72-80.

20. Ferreri AJ, Ponzoni M, Guidoboni M, et al. Evidence for an association between Chlamydia psittaci and ocular adnexal lymphomas. J Natl Cancer Inst. 2004;96:576-584.

21. Ferreri AJ, Guidoboni M, Ponzoni M, et al. Regression of ocular adnexal lymphoma after Chlamydia psittaci-eradicating antibiotic therapy. J Clin Oncol. 2005;23:5067-5073.

22. Conconi A, Martinelli G, Thieblemont C, et al. Clinical activity of rituximab in extranodal marginal zone B-cell lymphoma of MALT type. Blood. 2003;102:2741-2745.

23. Lossos IS, Morgensztern D, Blaya M, Alencar A, Pereira D, Rosenblatt J. Rituximab for treatment of chemoimmunotherapy naive marginal zone lymphoma. Leuk Lymphoma. 2007;48:1630-1632.

24. Raderer M, Jäger G, Brugger S, et al. Rituximab for treatment of advanced extranodal marginal zone B cell lymphoma of the mucosa-associated lymphoid tissue lymphoma. Oncology. 2003;65:306-310.

25. Nückel H, Meller D, Steuhl K-P, Dührsen U. Anti-CD20 monoclonal antibody therapy in relapsed MALT lymphoma of the conjunctiva. Eur J Haematol. 2004;73:258-262.

26. Ferreri AJM, Ponzoni M, Martinelli G, et al. Rituximab in patients with mucosal-associated lymphoid tissue-type lymphoma of the ocular adnexa. Haematologica. 2005;90:1578-1579.

27. Benetatos L, Alymara V, Asproudis I, Bourantas KL. Rituximab as first line treatment for MALT lymphoma of extraocular muscles. Ann Hematol. 2006;85:625-626.

28. Heinz C, Merz H, Nieschalk M, Mueller-Miny H, Koch P, Heiligenhaus A. Rituximab for the treatment of extranodal marginal zone B-cell lymphoma of the lacrimal gland. Br J Ophthalmol. 2007;91:1563-1564. 